\title{
GERMINAÇÃO DE SEMENTES DE PAU-FERRO SUBMETIDAS A DIFERENTES CONDIÇÕES DE ARMAZENAMENTO, ESCARIFICAÇÃO QUÍMICA, TEMPERATURA E LUZ ${ }^{1}$
}

\author{
ROSANGELA PERES BIRUEL ${ }^{2}$, IVOR BERGEMANN DE AGUIAR ${ }^{3}$, RINALDO CESAR DE PAULA $^{4}$
}

\begin{abstract}
RESUMO - Caesalpinia leiostachya (Benth.) Ducke (pau-ferro) é uma planta arbórea nativa do Brasil, cujas sementes possuem dormência causada pela impermeabilidade do tegumento à água. Neste trabalho foram conduzidos dois experimentos, nos quais foram utilizados diferentes períodos de escarificação em ácido sulfúrico concentrado para superar a dormência das sementes. No primeiro experimento, sementes coletadas em agosto de 1997 foram armazenadas por oito meses em ambiente não controlado no interior do próprio fruto, e em câmara seca após serem extraídas dos frutos; a seguir, elas foram imersas em ácido sulfúrico por 0, 10, 20, 40, 60 e 80min e colocadas para germinar nas temperaturas constante de $25^{\circ} \mathrm{C}$ e alternada de $20^{\circ}-30^{\circ} \mathrm{C}$, sob fotoperíodo de $8 \mathrm{~h}$. No segundo experimento, sementes extraídas de frutos recém-coletados em agosto de 1998 foram imersas em ácido sulfúrico por 0, 10, 20, 30, 40 e 60min, seguido do teste de germinação conduzido nas mesmas temperaturas do experimento anterior, na ausência e presença de luz. Foram avaliados a porcentagem final e o índice de velocidade de germinação das sementes. Os resultados mostraram que (a) a manutenção das sementes no interior dos frutos é uma alternativa viável para o armazenamento durante o período adotado; (b) as sementes recém-coletadas são indiferentes à luz, nas duas temperaturas testadas; (c) as sementes recém-coletadas e as armazenadas germinam em maior velocidade a $25^{\circ} \mathrm{C}$; (d) em sementes armazenadas, a imersão em ácido sulfúrico por 10min é suficiente para superar a dormência; (e) em sementes recém-coletadas, a imersão em ácido sulfúrico por 20 a 30min favorece a porcentagem e a velocidade de germinação.
\end{abstract}

Termos para indexação: Semente florestal, dormência, qualidade fisiológica.

\section{GERMINATION OF Caesalpinia leiostachya (Benth.) Ducke SEEDS UNDER DIFFERENT CONDITIONS OF STORAGE, CHEMICAL SCARIFICATION, TEMPERATURE AND LIGHT}

\begin{abstract}
Caesalpinia leiostachya (Benth.) Ducke (Caesalpinaceae) is a tree species native to Brazil, whose seed dormancy is imposed by a waterproof coat. In this study two experiments using different periods of seed immersion in concentrated sulphuric acid in order to break dormancy were carried out. In the first experiment, seeds collected in August 1997 were stored for eight months either at room temperature inside the fruits or under dry chamber conditions after their extraction from the fruits. After storage, the seeds were immersed in sulphuric acid for 0, 10, 20, 40, 60, and 80 min and germination tests were conducted at constant $\left(25^{\circ} \mathrm{C}\right)$ and alternating $\left(20^{\circ}-30^{\circ} \mathrm{C}\right)$ temperatures, under an eight hour photoperiod. The second experiment was carried out with seeds extracted from fruits collected in August 1998 and immediately immersed in sulphuric acid for $0,10,20,30,40,50$, and $60 \mathrm{~min}$. Germination tests were conducted at $25^{\circ} \mathrm{C}$ and $20-30^{\circ} \mathrm{C}$, in darkness and under white light. Both germination total percentage and speed of germination index were evaluated. The results showed that (a) the storage of seeds inside of fruits during the considered period is a viable alternative; (b) fresh seeds are indifferent to light at the two tested temperatures; (c) germination speed index either of fresh or of stored seeds is higher at $25^{\circ} \mathrm{C}$; (d) seed storage brought about a reduction in dormancy level so that exposing them to sulphuric acid for 10 minutes was enough to overcome seed dormancy; (e) in recently harvested seeds, the period of time of exposition to sulphuric acid needed to break dormancy was found to be between 20 and 30 minutes.
\end{abstract}

Index term: tree seed, dormancy, physiological quality

\footnotetext{
1 Submetido em 26/11/2005. Aceito para publicação em 29/06/2007. Parte da dissertação da primeira autora, apresentada ao Programa de PósGraduação em Agronomia (Produção e Tecnologia de Sementes) da FCAV-UNESP.

2 Bióloga, Dra ${ }^{a}$; bolsista CNPq (mestrado) e CAPES (doutorado); e-mail: peresbiruel@ hotmail.com

3 Prof. Titular Voluntário, Depto. de Produção Vegetal, FCAV-UNESP, bolsista CNPq, Via de Acesso Prof. Paulo Donato Castellane s/n, 14884900. Jaboticabal, SP; e-mail: ivor@ netsite.com.br

4 Prof. Adjunto, Depto. de Produção Vegetal, FCAV-UNESP, bolsista CNPq; e-mail: rcpaula@ fcav.unesp.br.
} 


\section{INTRODUÇÃO}

Caesalpinia leiostachya (Benth.) Ducke pertence à família Caesalpiniaceae, de acordo com o Sistema de Classificação de Cronquist, sendo conhecida popularmente por pau-ferro (Carvalho, 2003). É uma planta arbórea de grande porte que pode atingir cerca de $30 \mathrm{~m}$ de altura e ocorre do Piauí a São Paulo (Lorenzi, 1992), na floresta estacional semidecidual, na floresta ombrófila densa, na caatinga/mata seca e nos brejos de altitude (Carvalho, 1994). Produz madeira de uso múltiplo, de elevada densidade e longa durabilidade natural, sendo recomendada para reflorestamentos mistos destinados à recuperação de áreas degradadas (Lorenzi, 1992; Carvalho, 1994). Na caatinga nordestina, suas folhas são utilizadas como forrageiras (Crepaldi et al., 1998).

No Estado de São Paulo, floresce principalmente em janeiro e fevereiro e os frutos amadurecem em junho e julho (Figliolia e Piña-Rodrigues, 1995). Os frutos são secos, do tipo vagem e, na maturação, adquirem coloração escura; por serem indeiscentes e de casca dura, podem ser coletados no chão após queda espontânea. A extração das sementes pode ser feita manualmente, com o uso de martelo, ou mecanicamente, com o uso de triturador de café (Lorenzi, 1992; Silva et al., 1993; Carvalho, 1994).

As sementes de pau-ferro têm dormência devido à impermeabilidade do tegumento à água, como já foi observado por Grus et al. (1984), Barbosa et al. (1996), Crepaldi et al. (1998) e Lopes et al. (1998), e relatado por Carvalho (1994). Sementes com tegumento impermeável à água caracterizam-se por possuir uma camada paliçádica de células macroesclereídes na testa (Rolston, 1978).

Barbosa (1982) verificou que, sem tratamento prégerminativo, a germinação das sementes de pau-ferro é lenta e irregular, demorando até 91 dias para iniciar a germinação. Dessa forma, é necessária a aplicação de tratamento pré-germinativo para promover, acelerar e uniformizar a germinação das sementes dessa espécie. $\mathrm{O}$ tratamento adotado para superar a dormência causada pela impermeabilidade do tegumento à água é denominado de escarificação e visa romper o tegumento (Ramos e Zanon, 1986).

Alguns autores, como Grus et al. (1984), Barbosa et al. (1986), Crepaldi et al. (1998) e Lopes et al. (1998) testaram diferentes tratamentos de escarificação visando superar a dormência das sementes de pau-ferro. Geralmente a A escarificação mecânica (lixação) e química (imersão em ácido sulfúrico concentrado) conduziu aos melhores resultados, que variaram em função do período de imersão e do lote utilizado. A lixação, entretanto, tem aumentado a contaminação por fungos durante a condução do teste de germinação, conforme constatado por Grus et al. (1984).

As sementes que possuem tegumento impermeável à água geralmente são de elevada longevidade natural (Zanon e Ramos, 1986), podendo ser acondicionadas em embalagem permeável e armazenadas em ambiente não controlado (Silva e Moraes, 1986). Nessa condição, as sementes de pau-ferro podem permanecer viáveis por mais de 15 meses (Lorenzi, 1992); contudo, Carvalho (1994) relatou que as sementes dessa espécie não têm boa conservação, mesmo quando armazenadas em câmara seca.

No trabalho desenvolvido por Barbosa (1982), as sementes de pau-ferro permaneceram armazenadas em câmara seca por aproximadamente 50 dias e o autor atribuiu ao armazenamento nessas condições uma possível isso uma possível interferência negativa na porcentagem e na velocidade de germinação. Grus et al. (1984) utilizaram sementes acondicionadas dentro de frutos armazenados em local abrigado, porém não controlado, por cerca de seis meses. Não existe pesquisa, entretanto, comparando o armazenamento das sementes no interior dos frutos com o das extraídas dos mesmos.

Outros fatores que influenciam a germinação das sementes são a temperatura e a luz, podendo haver interação entre os mesmos, como salientaram Lagôa e Pereira (1987). Assim, a germinação das sementes pode ser afetada pelo regime de temperatura e pela condição de luz, ou ser indiferente a esses fatores (Borges e Rena, 1993; Figliolia et al., 1993).

Nos trabalhos já realizados com sementes de pau-ferro, foram adotadas diferentes condições para a condução do teste de germinação. Considerando que os fatores abordados foram testados de forma isolada, neste trabalho foram conduzidos dois experimentos, testando esses fatores simultaneamente e utilizando diferentes períodos de imersão em ácido sulfúrico para superar a dormência das sementes. O objetivo do primeiro experimento foi estudar o efeito da condição de armazenamento e da temperatura na germinação de sementes armazenadas, enquanto que o do 
segundo foi estudar o efeito da luz e da temperatura na germinação de sementes recém-coletadas.

\section{MATERIAL E MÉTODOS}

As sementes de pau-ferro utilizadas neste trabalho foram extraídas de frutos coletados da superfície do solo, em um agrupamento de árvores localizado no campus da Faculdade de Ciências Agrárias e Veterinárias (FCAV) da Universidade Estadual Paulista (UNESP), no município de Jaboticabal, SP. Esse campus está situado a $21^{\circ} 16^{\prime} \mathrm{S}$ e $48^{\circ}$ $19^{\prime}$ W, a $575 \mathrm{~m}$ de altitude; segundo a classificação climática de Köppen, o clima da região é de transição entre os tipos Cwa e Aw (Ventura et al., 1965/66).

O primeiro experimento foi instalado com frutos coletados em agosto de 1997, sendo uma parte submetida ao armazenamento em ambiente natural de laboratório, sem controle da temperatura e da umidade relativa do ar. Os frutos restantes foram abertos manualmente, com uso de martelo, sendo as sementes armazenadas em câmara seca dotada de um desumidificador, com umidade relativa do ar de $42 \% \pm 3 \%$ e temperatura de $25 \% \pm 5^{\circ} \mathrm{C}$.

Após oito meses de armazenamento nas duas condições mencionadas, foram instalados testes de germinação no Laboratório de Sementes Hortícolas e Florestais da FCAV/ UNESP. Antes da instalação dos testes, as sementes foram escarificadas com ácido sulfúrico $1 \mathrm{~N}$ (95\%-98\% p.a.) pelos períodos de 0 (controle), 10, 20, 40, 60 e 80min.

No segundo experimento foram utilizadas sementes extraídas de frutos coletados em agosto de 1998, cujos testes de germinação foram instalados logo após a coleta dos frutos e a extração das sementes. Foram adotados os seguintes períodos de escarificação com ácido sulfúrico 1 N (95\%-98\% p.a.): 0 (controle), 10, 20, 30, 40, 50 e 60min.

Nos dois experimentos, os testes de germinação foram conduzidos em germinadores de câmara regulados para as temperaturas constante de $25^{\circ} \mathrm{C}$ e alternada de $20^{\circ}-30^{\circ} \mathrm{C}$, sob fotoperíodo de $8 \mathrm{~h}$. No segundo experimento os testes foram conduzidos, também, na ausência de luz.

A escarificação química foi efetuada seguindo as Regras para Análise de Sementes (Brasil, 1992), ou seja, após a imersão das sementes no ácido pelos diferentes períodos, elas foram lavadas em água corrente até eliminar os resíduos do mesmo. Outrossim, antes da instalação dos testes de germinação, as sementes foram imersas em solução de hipoclorito de sódio a $2 \%$ por $4 \mathrm{~min}$ e, a seguir, lavadas com água destilada.

As sementes de cada tratamento foram semeadas sobre $40 \mathrm{~g}$ de vermiculita de granulometria média previamente autoclavada e umedecida com $60 \mathrm{~mL}$ de água destilada, em caixas de plástico de $11 \times 11 \times 4 \mathrm{~cm}$, com tampa. Nos tratamentos referentes ao fotoperíodo, foram utilizadas caixas transparentes e a luz foi fornecida por lâmpadas

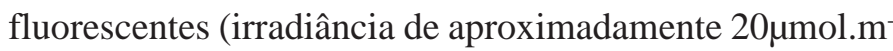
${ }^{2} . \mathrm{s}^{-1}$, segundo Valio e Scarpa, 2001). No caso da temperatura alternada, o período luminoso correspondeu à temperatura mais elevada. Nos tratamentos sem luz, foram utilizadas caixas de coloração preta e os testes foram instalados e avaliados sob luz verde de segurança (espectro de $0,02 \mu \mathrm{W} \cdot \mathrm{cm}^{-2} . \mathrm{nm}$, conforme Lopes e Soares, 2003).

O período de duração dos testes de germinação foi de 14 dias, tendo sido feita contagem diária das sementes germinadas, cuja raiz primária se apresentou com pelo menos $1 \mathrm{~cm}$ de comprimento. Foram avaliadas a porcentagem final e a velocidade de germinação das sementes, esta última representada pelo índice calculado pela fórmula descrita por Maguire (1962), considerando o critério botânico de germinação (Labouriau, 1983).

Foi adotado o delineamento experimental inteiramente casualizado e as análises de variância foram efetuadas sob o esquema fatorial. Os fatores testados foram condição de armazenamento, temperatura e período de escarificação, no primeiro experimento, e temperatura, luz e período de escarificação no segundo experimento. Foram adotadas três repetições de 20 sementes para cada tratamento. Os dados em porcentagem foram submetidos ao teste de normalidade de Liliefors (Cruz, 2001), não havendo necessidade de transformação. A comparação entre as médias foi feita com a aplicação do teste de Tukey, a 5\% de probabilidade. Quando foi constatada significância para período de escarificação, foi feita análise de regressão polinomial. Considerando que sem tratamento pré-germinativo (controle) as sementes não germinaram, apenas os dados obtidos com as sementes escarificadas foram submetidos à análise estatística. 


\section{RESULTADOS E DISCUSSÃO}

Nos dois experimentos as sementes não escarificadas (controle) não germinaram, indicando que elas estavam dormentes; por outro lado, as sementes escarificadas germinaram em porcentagem que variou de $28 \%$ a $95 \%$ (Tabelas 1 e 2). Em sementes impermeáveis à água, a ação do ácido sulfúrico no enfraquecimento do tegumento pode ser resultado da remoção da cutícula e conseqüente exposição das camadas de macroesclereídes (Perez, 2004). Considerando que não foi constatada interação significativa entre os três fatores testados, para cada experimento, os valores contidos nas tabelas e nas figuras representam as médias gerais de cada fator, incluindo os dados referentes aos outros dois fatores.

Pela analise dos resultados obtidos no primeiro experimento, as sementes armazenadas no interior dos frutos, em ambiente não controlado, apresentaram maiores porcentagem e velocidade de germinação do que as extraídas dos frutos e armazenadas na câmara seca (Tabela 1). $O$ fruto de pau-ferro é muito lenhoso e extremamente duro (Oliveira, 1997), tendo provavelmente protegido as sementes contra as variações das condições ambientais. Essa forma de armazenamento já havia sido utilizada por Grus et al. (1984) e pode ser uma alternativa viável, pelo menos a curto prazo (entre coleta de dois anos consecutivos).

Para as sementes escarificadas, não houve efeito significativo do período de escarificação na germinação. A porcentagem de germinação não foi afetada pela temperatura, mas as sementes germinaram mais rapidamente na temperatura $25^{\circ} \mathrm{C}$.

No segundo experimento, os resultados referentes à temperatura confirmaram aqueles verificados no experimento anterior: não houve efeito significativo na porcentagem de germinação, mas as sementes germinaram mais rapidamente na temperatura constante de $25^{\circ} \mathrm{C}$ (Tabela 2). As sementes germinaram de forma similar na ausência e na presença de luz, concordando com os resultados obtidos por Crepaldi et al. (1998) que testaram diferentes fotoperíodos, e a interação entre luz e temperatura não foi significativa.

A germinação das sementes, em relação à temperatura e à luz, é uma resposta ecofisiológica da espécie que está associada ao estádio sucessional na floresta (Jesus e PiñaRodrigues, 1991; Figliolia et al., 1993). O pau-ferro é uma espécie dos estádios finais da sucessão secundária, sendo classificada por Carvalho (1994) como secundária tardia a clímax e por Ferretti et al. (1995) como clímax. As sementes desses grupos ecológicos normalmente germinam sob o dossel, onde a temperatura é relativamente constante e a luz é filtrada pela folhagem da copa das árvores (VázquezYanes e Orozco-Segovia, 1984). Assim, a maior velocidade de germinação das sementes de pau-ferro, observada na temperatura constante, é compatível com a característica ecofisiológica da espécie. Segundo Piña-Rodrigues et al. (1990) e Kageyama e Viana (1991), a germinação das sementes das espécies secundárias tardias, também denominadas de oportunistas, é pouco afetada por fatores como temperatura e luz.

$\mathrm{Na}$ natureza, a sucessão secundária ocorre com a formação de clareiras na floresta primária, que permite a entrada de luz e promove a alternância da temperatura do solo, condições adequadas para a germinação das sementes das espécies pioneiras. $\mathrm{O}$ fato das sementes de pau-ferro terem germinado bem nas duas temperaturas, bem como na presença e ausência de luz, permite considerar que elas possam ser capazes de germinar, também, em clareiras. Dessa forma, essa espécie pode ser enquadrada entre aquelas que Kageyama e Gandara (2000) consideram secundárias/pioneiras antrópicas, ou seja, espécies secundárias e normalmente raras na floresta, mas que em áreas antrópicas desempenham a função de pioneiras.

Quanto à superação da dormência, foi constatado efeito significativo do período de escarificação (Tabela 2) e as análises de regressão revelaram que os dados se ajustaram aos modelos cúbico para a porcentagem e quadrático para a velocidade de germinação. Os melhores resultados foram obtidos entre 20 e 30min de imersão no ácido sulfúrico, como evidenciam as Figuras 1 e 2. Percebe-se que esses dois parâmetros apresentam comportamento distinto frente ao mesmo fator. Assim, para a porcentagem de germinação o período ótimo estimado foi de 21,4min, enquanto que para o índice de velocidade esse período foi de $27,5 \mathrm{~min}$.

A imersão por 10min foi insuficiente para o completo rompimento do tegumento e os períodos superiores a 30min reduziram a germinação das sementes. Esse resultado difere daquele obtido no primeiro experimento (Tabela 1), no qual as sementes escarificadas por 10 a 80 min germinaram de 
TABELA 1. Porcentagem (\%G) e índice de velocidade (IVG) de germinação das sementes de Caesalpinia leiostachya (Benth.) Ducke (pau-ferro) armazenadas por oito meses em duas condições, escarificadas com ácido sulfúrico por diferentes períodos e submetidas a duas temperaturas. Lote coletado em Jaboticabal (SP) em agosto de 1997.

\begin{tabular}{|c|c|c|c|}
\hline Fator & Condição & $\% \mathrm{G}$ & IVG \\
\hline \multirow{2}{*}{ Condição de armazenamento } & Fruto & $79 \mathrm{a}$ & $2,20 \mathrm{a}$ \\
\hline & Semente & $72 \mathrm{~b}$ & $1,86 \mathrm{~b}$ \\
\hline \multirow{2}{*}{ Temperatura } & Constante & $77 \mathrm{a}$ & $2,12 \mathrm{a}$ \\
\hline & Alternada & $74 \mathrm{a}$ & $1,94 \mathrm{~b}$ \\
\hline \multirow{5}{*}{ Período de escarificação } & $10 \mathrm{~min}$ & 77 & 1,87 \\
\hline & $20 \mathrm{~min}$ & 76 & 1,96 \\
\hline & $40 \mathrm{~min}$ & 74 & 2,04 \\
\hline & $60 \mathrm{~min}$ & 79 & 2,21 \\
\hline & $80 \mathrm{~min}$ & 73 & 2,06 \\
\hline \multicolumn{2}{|c|}{ Valor de F para condição de armazenamento (A) } & $6,93 *$ & $19,64 * *$ \\
\hline \multicolumn{2}{|c|}{ Valor de F para temperatura $(\mathrm{T})$} & $1,08^{\mathrm{ns}}$ & $5,69 *$ \\
\hline \multicolumn{2}{|c|}{ Valor de F para período de escarificação (E) } & $0,59^{\mathrm{ns}}$ & $1,14^{\mathrm{ns}}$ \\
\hline \multicolumn{2}{|c|}{ Valor de F para a interação $(\mathrm{A} \times \mathrm{T})$} & $3,60^{\mathrm{ns}}$ & $0,37^{\mathrm{ns}}$ \\
\hline \multicolumn{2}{|c|}{ Valor de $\mathrm{F}$ para a interação $(\mathrm{A} \times \mathrm{E})$} & $0,79^{\mathrm{ns}}$ & $0,81^{\mathrm{ns}}$ \\
\hline \multicolumn{2}{|c|}{ Valor de $\mathrm{F}$ para a interação (T x E) } & $0,79^{\mathrm{ns}}$ & $1,29^{\text {ns }}$ \\
\hline \multicolumn{2}{|c|}{ Coeficiente da variação } & $13,95 \%$ & $14,62 \%$ \\
\hline
\end{tabular}

(a,b) Para cada fator testado, em cada coluna, médias seguidas de mesma letra não diferem entre si pelo teste de Tukey $(p>0,05)$. (ns) Não significativo: $\mathrm{p}>0,05 ;(*)$ significativo: $\mathrm{p}<0,05 ;(* *)$ significativo: $\mathrm{p}<0,01$.

TABELA 2. Porcentagem (\%G) e índice de velocidade (IVG) de germinação das sementes recém-coletadas de Caesalpinia leiostachya (Benth.) Ducke (pau-ferro) escarificadas com ácido sulfúrico por diferentes períodos e submetidas a duas temperaturas e condições de luz. Lote coletado em Jaboticabal (SP) em agosto de 1998.

\begin{tabular}{llcc}
\hline Fator & Condição & $\% \mathrm{G}$ & IVG \\
\hline \multirow{2}{*}{ Temperatura } & Constante & $66 \mathrm{a}$ & $1,79 \mathrm{a}$ \\
& Alternada & $67 \mathrm{a}$ & $1,34 \mathrm{~b}$ \\
\hline \multirow{2}{*}{ Condição de luz } & Ausência & $68 \mathrm{a}$ & $1,61 \mathrm{a}$ \\
& Presença & $65 \mathrm{a}$ & $1,51 \mathrm{a}$ \\
\hline & $10 \mathrm{~min}$ & 80 & 1,61 \\
& $20 \mathrm{~min}$ & 86 & 1,79 \\
Período de escarificação & $30 \mathrm{~min}$ & 95 & 2,19 \\
& $40 \mathrm{~min}$ & 65 & 1,67 \\
& $50 \mathrm{~min}$ & 45 & 1,29 \\
\hline Valor de F para temperatura (T) & $60 \mathrm{~min}$ & 28 & 0,82 \\
Valor de F para condição de luz (L) & & $0,18^{\mathrm{ns}}$ & $24,69^{* *}$ \\
Valor de F para período de escarificação (E) & $2,23^{\mathrm{ns}}$ & $1,28^{\mathrm{ns}}$ \\
Valor de F para a interação (T x L) & & $65,22^{* *}$ & $17,71^{* *}$ \\
Valor de F para a interação (T x E) & & $0,92^{\mathrm{ns}}$ & $0,73^{\mathrm{ns}}$ \\
Valor de F para a interação (L x E) & & $1,78^{\mathrm{ns}}$ & $0,21^{\mathrm{ns}}$ \\
\hline Coeficiente da variação & $2,36^{\mathrm{ns}}$ & $1,32^{\mathrm{ns}}$ \\
\hline
\end{tabular}

(a,b) Para cada fator testado, em cada coluna, médias seguidas de mesma letra não diferem entre si pelo teste de Tukey $(\mathrm{p}>0,05) .(\mathrm{ns})$ Não significativo: $p>0,05 ;(* *)$ significativo: $p<0,01$. 


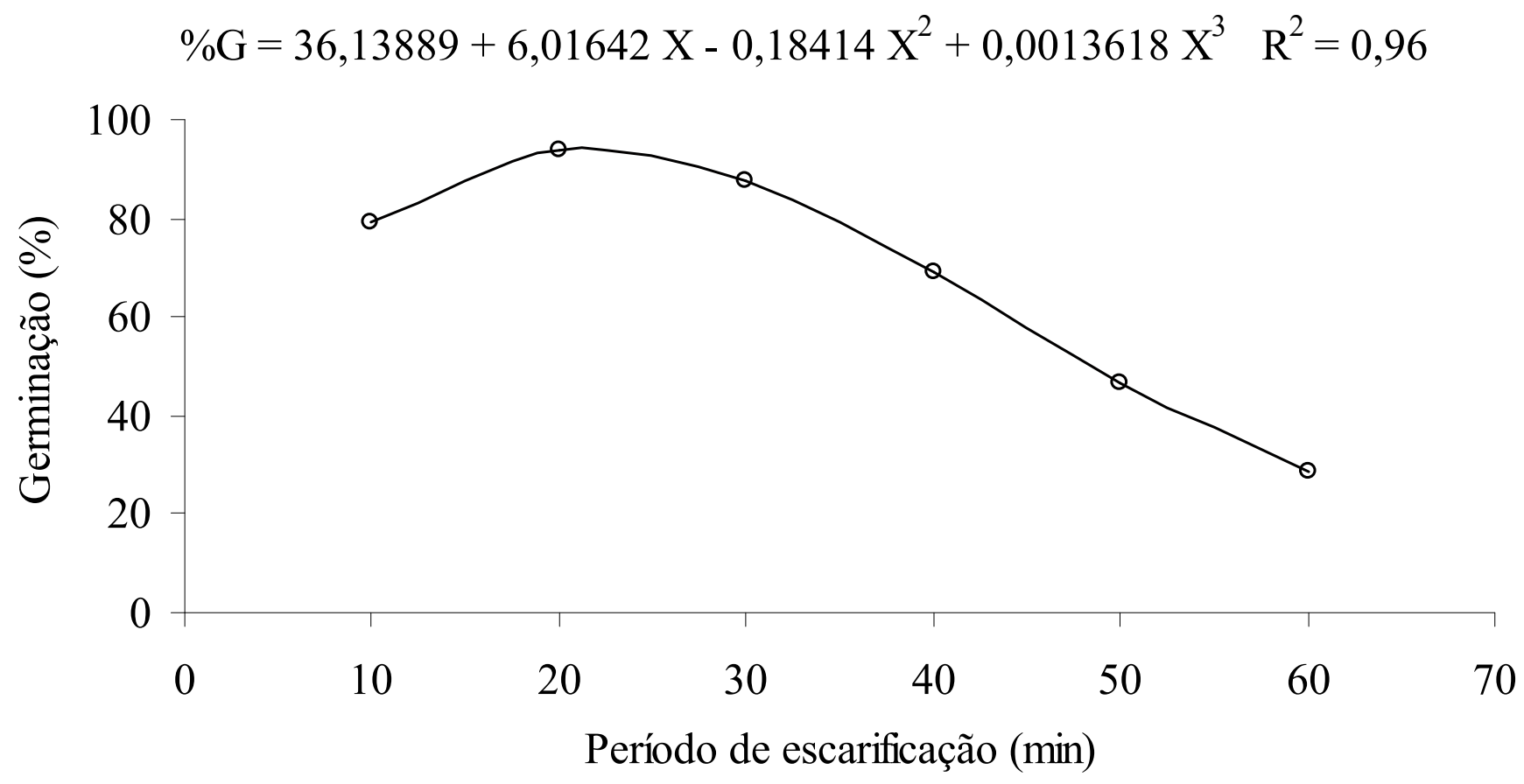

FIGURA 1. Porcentagem de germinação das sementes recém-coletadas de Caesalpinia leiostachya (Benth.) Ducke (pau-ferro) escarificadas com ácido sulfúrico por diferentes períodos. Lote coletado em Jaboticabal (SP) em agosto de 1998.

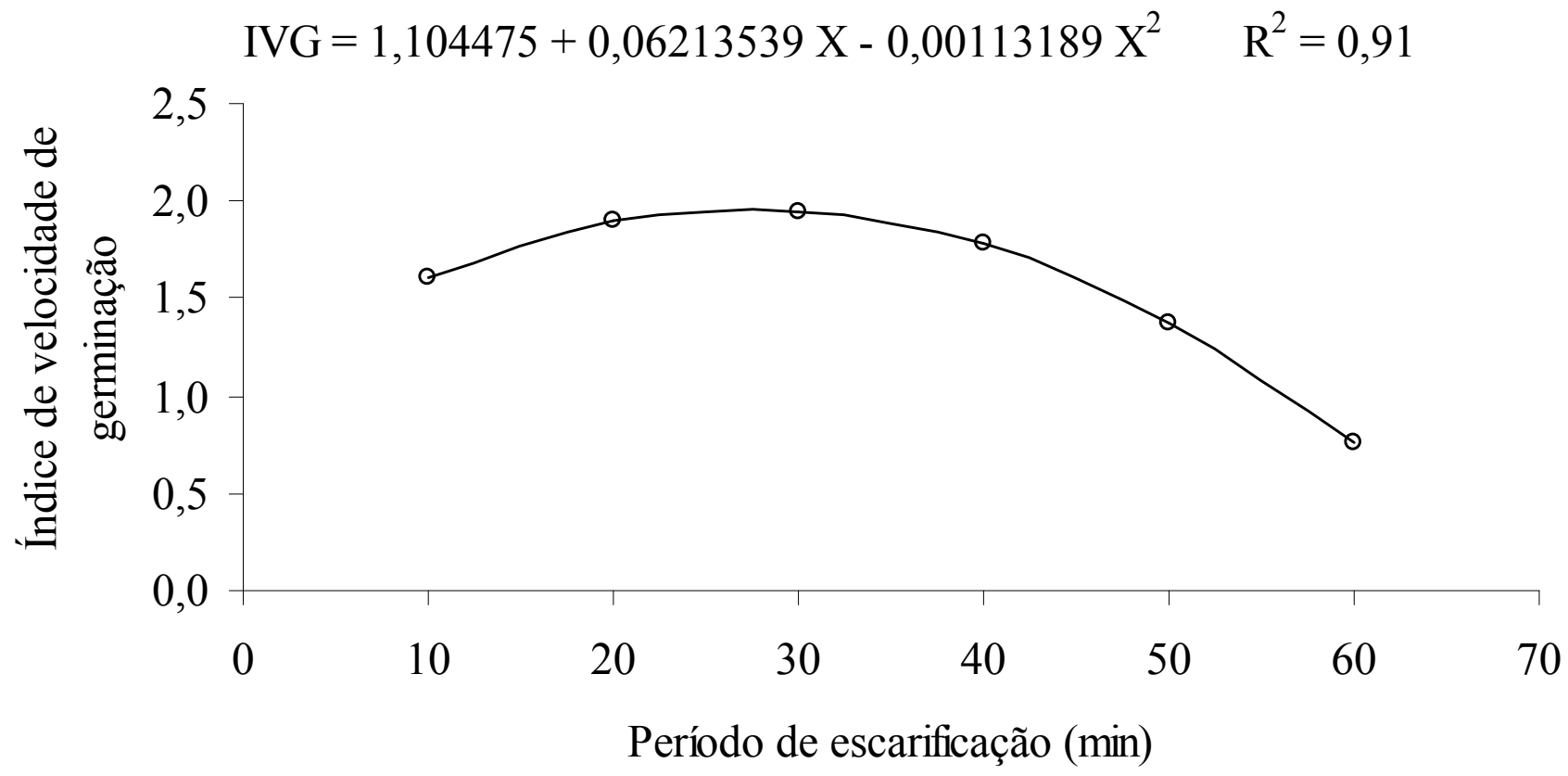

FIGURA 2. Índice de velocidade de germinação das sementes recém-coletadas de Caesalpinia leiostachya (Benth.) Ducke (pau-ferro) escarificadas com ácido sulfúrico por diferentes períodos. Lote coletado em Jaboticabal (SP) em agosto de 1998. 
forma similar. Segundo Marcos Filho (2005), a intensidade de dormência é maior em sementes recém-colhidas e tende a diminuir gradativamente à medida que elas envelhecem. Perez (2004) ressaltou que flutuações da temperatura do ambiente são as principais causas do enfraquecimento do tegumento em sementes de muitas espécies.

É importante ressaltar que no primeiro experimento as sementes permaneceram armazenadas por oito meses e suportaram a imersão em ácido sulfúrico por até $80 \mathrm{~min}$ (Tabela 1), enquanto que no segundo experimento houve expressiva redução na germinação das sementes recémcoletadas, com apenas 40min de imersão (Tabela 2, Figuras 1 e 2). Esses resultados sugerem que durante o armazenamento, apesar do enfraquecimento do tegumento, as sementes ficaram mais resistentes à ação do ácido. Concordando com essa colocação, Lopes et al. (1998) também submeteram sementes armazenadas de pau-ferro à imersão em ácido sulfúrico por períodos de 5 a 60 min e concluíram pela recomendação de $60 \mathrm{~min}$ de imersão, indicando que as sementes armazenadas resistiram ao maior período de escarificação.

No artigo publicado por Barbosa et al. (1996), foi feito um ensaio preliminar com sementes recém-coletadas, que foram submetidas a 1, 5, 10, 30 e 60min de imersão em ácido sulfúrico a fim de selecionar o tratamento a ser testado no ensaio principal. Melhores resultados foram obtidos com 30 min de imersão, indicando que as sementes não suportaram um período mais prolongado de escarificação. Esses resultados concordam com os constatados no segundo experimento do presente trabalho, também realizado com sementes recém-coletadas, e reforçam a suposição feita com base no primeiro experimento, de que as sementes armazenadas são mais resistentes à ação do ácido sulfúrico. De acordo com Marcos Filho (2005), a avaliação dos efeitos dos tratamentos para superar a dormência deve ser feita com o devido cuidado, pois determinado tratamento capaz de desativar o bloqueio e permitir a germinação das sementes dormentes pode prejudicar o desempenho das sementes não dormentes.

A diferença observada nos diferentes trabalhos comprova a afirmação de Carvalho (1994) de que a intensidade de dormência das sementes de pau-ferro varia entre lotes. Estudos ontológicos indicam que a impermeabilidade do tegumento é adquirida na fase final do desenvolvimento das sementes e varia entre sementes da mesma espécie, coletadas em diferentes locais e anos (Rolston, 1978), em decorrência das variações ocorridas na duração do dia, nutrição mineral e disponibilidade de água (Perez, 2004).

Assim, para fins de produção de mudas, bem como para a condução do teste de germinação, é recomendável a realização de um teste preliminar para cada lote de sementes, visando definir o período de escarificação a ser adotado. $\mathrm{O}$ manuseio do ácido sulfúrico exige cuidados, que normalmente já são do conhecimento dos laboratoristas, e devem ser seguidos com muita atenção. Com base nos resultados obtidos neste trabalho, o teste de germinação com sementes de pau-ferro pode ser realizado na presença ou ausência de luz e na temperatura constante de $25^{\circ} \mathrm{C}$.

\section{CONCLUSÕES}

A manutenção das sementes de pau-ferro no interior dos frutos é uma alternativa viável para o armazenamento durante pelo menos o período de oito meses.

As sementes recém-coletadas germinam de forma similar na presença e ausência de luz após a escarificação, nas duas temperaturas testadas $\left(25^{\circ} \mathrm{C}\right.$ e $\left.20^{\circ}-30^{\circ} \mathrm{C}\right)$.

As sementes recém-coletadas e as armazenadas por oito meses germinam em maior velocidade na temperatura constante de $25^{\circ} \mathrm{C}$, após a escarificação.

Em sementes armazenadas, a imersão em ácido sulfúrico por 10min é suficiente para superar a dormência causada pela impermeabilidade do tegumento à água.

Em sementes recém-colhidas, a imersão em ácido sulfúrico por 20 a 30min favorece a porcentagem e a velocidade de germinação.

\section{REFERÊNCIAS}

BARBOSA, E.; SILVA, M. M.; ROCHA, F. R.; QUEIROZ, L. P.; CREPALDI, I. C. Germinação de sementes de Cratylia molis Mart. ex Benth. e Caesalpinia ferrea Mart. ex Tul. (Leguminosae) submetidas a tratamento para quebra da impermeabilidade do tegumento. Sitientibus, Feira de Santana, n.15, p.183-192, 1996.

BARBOSA, J. M. Germinação de sementes de sete essências nativas. Silvicultura em São Paulo, São Paulo, v.16, n.1, p.322327, 1982.

BORGES, E. E. L.; RENA, A. B. Germinação de sementes. In: AGUIAR, I.B.; PIÑA-RODRIGUES, F.C.M.; FIGLIOLIA, M.B. (Coord.). Sementes florestais tropicais. Brasília: ABRATES, 1993. p.83-135. 
BRASIL. Ministério da Agricultura e da Reforma Agrária. Regras para análise de sementes. Brasília: SNDA/DNDV/CLAV, 1992. $365 \mathrm{p}$.

CARVALHO, P. E. R. Caesalpinia leiostachya (Bentham) Ducke. In: CARVALHO, P. E. R. (Ed.). Espécies florestais brasileiras: recomendações silviculturais, potencialidades e uso da madeira. Colombo: CNPF/EMBRAPA, 1994. p.118-122.

CARVAlHO, P. E. R. Pau-Ferro: Caesalpinia ferrea var. parvifolia. In: CARVALHO, P. E. R. (Ed.). Espécies arbóreas brasileiras. Colombo: Embrapa Florestas, 2003. v.1, p.745-749.

CREPALDI, I. C.; SANTANA, J. R. F.; LIMA, P. B. Quebra de dormência de sementes de pau-ferro (Caesalpinia ferrea Mart. ex Tul. - Leguminosae, Caesalpinioideae). Sitientibus, Feira de Santana, n.18, p.19-29, 1998.

CRUZ, C. D. Programa GENES: versão Windows; aplicativo computacional em genética e estatística. Viçosa: UFV, 2001. 648p.

FERRETTI, A. R.; KAGEYAMA, P. Y.; ÁRBOCZ, G. F.; SANTOS, J.D.; BARROS, M. I. A.; LORZA, R. F.; OLIVEIRA, C. Classificação das espécies arbóreas em grupos ecológicos para revegetação com nativas no estado de São Paulo. Florestar Estatístico, São Paulo, v.3, n.7, p.73-77, 1995.

FIGLIOLIA, M. B.; OLIVEIRA, E. C.; PIÑA-RODRIGUES, F. C. M. Análise de sementes. In: AGUIAR, I. B.; PIÑA-RODRIGUES, F. C. M.; FIGLIOLIA, M. B. (Coord.). Sementes florestais tropicais. Brasília: ABRATES, 1993. p.137-174.

FIGLIOLIA, M. B.; PIÑA-RODRIGUES, F. C. M. Manejo de sementes de espécies arbóreas. São Paulo: Instituto Florestal, 1995. 59p. (IF Série Registros, 15).

GRUS, V. M.; DEMATTÊ, M. E. S. P.; GRAZIANO, T. T. Germinação de sementes de pau-ferro e cassia-javanesa submetidas a tratamentos para quebra de dormência. Revista Brasileira de Sementes, Brasília, v.6, n.2, p.29-35, 1984.

JESUS, R. M.; PIÑA-RODRIGUES, F. C. M. Programa de produção e tecnologia de sementes florestais da Florestas Rio Doce S.A.: uma discussão dos resultados obtidos. In: SIMPÓSIO BRASILEIRO SOBRE TECNOLOGIA DE SEMENTES FLORESTAIS, 2., 1989, Atibaia. Anais... São Paulo: Instituto Florestal, 1991.p.59-86.

KAGEYAMA, P. Y.; GANDARA, F. B. Recuperação de áreas degradadas. In: RODRIGUES, R. R.; LEITÃO FILHO, H. F. (Coord.). Matas ciliares: conservação e recuperação. São Paulo: USP/FAPESP, 2000. p.249-269.

KAGEYAMA, P. Y.; VIANA, V. M. Tecnologia de sementes e grupos ecológicos de espécies arbóreas tropicais. In: SIMPÓSIO BRASILEIROSOBRETECNOLOGIADESEMENTESFLORESTAIS, 2., 1989, Atibaia. Anais... São Paulo: Instituto Florestal, 1991. p.197215 .
LABOURIAU, L. G. Capacidade e velocidade de germinação. In: LABOURIAU, L. G. A germinação das sementes. Washington: Organização dos Estados Americanos, 1983. p.45-62.

LAGÔA, A. M. A.; PEREIRA, M. F. D. A. Fotoblastismo em sementes de Ricinus comunis. Revista Brasileira de Botânica, São Paulo, v.10, n.2, p.155-158, 1987.

LOPES, J. C.; CAPUCHO, M. T.; KROHLING, B.; ZANOTTI, P. Germinação de sementes de espécies florestais de Caesalpinia ferrea Mart. ex Tul. var. leiostachya Benth., Cassia grandis L. e Samanea saman Merrill, após tratamentos para superar a dormência. Revista Brasileira de Sementes, Brasília, v.20, n.1, p.80-86, 1998.

LOPES, J. C.; SOARES, A. S. Germinação de sementes de Miconia cinnamomifolia (DC.) Naud. Brasil Florestal, Brasília, n.75, p.3138, 2003.

LORENZI, H. Caesalpinia ferrea Mart. ex Tul. var. leiostachya Benth. In: LORENZI, H. (Ed.). Árvores brasileiras: manual de identificação e cultivo de plantas arbóreas nativas do Brasil. Nova Odessa: Editora Plantarum, 1992. p.147.

MAGUIRE, J. D. Speed of germination-aid in selection and evaluation for seedling emergence and vigor. Crop Science, Madison, v.2, n.2, p.176-177, 1962.

MARCOS FILHO. J. Dormência de sementes. In: MARCOS FILHO, J. (Ed.). Fisiologia de sementes de plantas cultivadas. Piracicaba: FEALQ, 2005. p.253-289.

OLIVEIRA, D. M. T. Análise morfológica comparativa de frutos, sementes, plântulas e plantas jovens de 30 espécies arbóreas de Fabaceae ocorrentes no estado de São Paulo. 1997. 212f. Tese (Doutorado em Biologia Vegetal) - Instituto de Biociências, Universidade Estadual Paulista, Rio Claro, 1997.

PEREZ, S. C. J. G. A. Envoltórios. In: FERREIRA, A. G.; BORGHETTI, F. (Org.). Germinação: do básico ao aplicado. Porto Alegre: Artmed, 2004. p.125-134.

PIÑA-RODRIGUES, F. C. M.; COSTA, L. G. S.; REIS, A. Estratégias de estabelecimento de espécies arbóreas e o manejo de florestas tropicais. In: CONGRESSO FLORESTAL BRASILEIRO, 6., 1990, Campos do Jordão. Anais... São Paulo: SBS/SBEF, 1990. v.3, p.676684.

RAMOS, A.; ZANON, A. Dormência em sementes de espécies florestais nativas. In: SIMPÓSIO BRASILEIRO SOBRE TECNOLOGIA DE SEMENTES FLORESTAIS, 1., 1984, Belo Horizonte. Anais... Brasília: ABRATES, 1986. p.241-265.

ROLSTON, M. P. Water impermeable seed dormancy. The Botanical Review, New York, v.44, n.3, p.365-396, 1978.

SILVA, A.; FIGLIOLIA, M. B.; AGUIAR, I. B. Secagem, extração e beneficiamento de sementes. In: AGUIAR, I. B.; PIÑARODRIGUES, F. C. M.; FIGLIOLIA, M. B. (Coord.). Sementes florestais tropicais. Brasília: ABRATES, 1993. p.303-331. 
SILVA, A.; MORAES, E. Programa de produção e tecnologia de sementes florestais desenvolvido pelo Instituto Florestal do Estado de São Paulo. In: SIMPÓSIO BRASILEIRO SOBRE TECNOLOGIA DE SEMENTES FLORESTAIS, 1., 1984, Belo Horizonte. Anais... Brasília: ABRATES, 1986. p.35-57.

VALIO, I. F. M.; SCARPA, F. M. Germination of seeds of tropical pioneer species under controlled and natural conditions. Revista Brasileira de Botânica, São Paulo, v.24, n.1, p.79-84, 2001.

VÁZQUEZ-YANES, C.; OROZCO-SEGOVIA, A. Fisiología ecológica de las semillas de árboles de la selva tropical: un reflejo de su ambiente. Ciencia, Santo Domingo, v.35, p.191-201, 1984.
VENTURA, A.; BERENGUT, G.; VICTOR, M. A. M. Características edafo-climáticas das dependências do Serviço Florestal do Estado de São Paulo. Silvicultura em São Paulo, São Paulo, v.4/5, n.4, p.57-140, 1965/66.

ZANON, A; RAMOS, A. Armazenamento de sementes de espécies florestais. In: SIMPÓSIO BRASILEIRO SOBRE TECNOLOGIA DE SEMENTES FLORESTAIS, 1., 1984. Belo Horizonte. Anais... Brasília: ABRATES, 1986. p.285-316. 